\title{
Desastres Naturais, Política de Agentes Internacionais e Vulnerabilidade no Haiti
}

\author{
Natural Disasters, International Agent Policy and Vulnerability in Haiti
}

\author{
Guerby Sainté \\ Instituto de Geociências, Departamento de Geografia \\ Universidade Estadual de Campinas - UNICAMP, Brasil \\ guerby20102010@gmail.com \\ Luca Lämmle \\ Universidade Estadual de Campinas - UNICAMP, Brasil \\ $\underline{\text { lucalammle@ige.unicamp.br }}$
}

\begin{abstract}
Resumo
O objetivo do presente trabalho foi fazer uma análise sobre os desastres naturais (terremotos, furacões, secas, entre outros) no Haiti, que são usados como justificativa para a ampliação de agentes internacionais no território sob auspício da ajuda humanitária para pessoas em situação de vulnerabilidade. Este processo foi intensificado após o terremoto de 2010. Nesse sentido, observouse como as instituições nacionais passaram a ser controladas por agentes internacionais neste processo, fazendo com que o país perdesse parte da autonomia e controle do seu território devido à constantes intervenções. Em adição, foi analisado como esse tipo de atuação pode contribuir para a continuação deste processo, uma vez que acaba atraindo e surgindo quantidade significativa de Organizações Não Governamentais (ONGs) para dar suporte à gestão de assistência social no Haiti. Para se chegar ao objetivo, foi analisada literatura especializada sobre desastres naturais, atuação de ONGs e vulnerabilidade no país em questão, além de pesquisa documental realizada em jornais, reportagens, relatórios e dados oficiais do governo local. Por fim, destaca-se que o Estado deve preparar um plano de investimento em infraestrutura e conscientizar a população a deixarem áreas consideradas de risco, criando mecanismos para que a mesma possa ser realocada para locais planejados. Assim, o Estado não será capaz de eliminar os riscos associados aos desastres naturais, mas reduzirá perdas em bens materiais e em vidas humanas.
\end{abstract}

Palavras-chave: Desastres Naturais; Vulnerabilidade; Agentes Internacionais; Soberania Territorial.

\begin{abstract}
This paper aimed to analyze the natural disasters (earthquake, hurricanes, droughts, among others) in Haiti, which are used to justify the expansion of international agents in the territory under the auspices of humanitarian aid for people in situations of vulnerability. This process was intensified after the 2010 earthquake. In this sense, it was observed how the national institutions started to be controlled by international agents, causing the country to lose part of the autonomy and control of its territory due to constant interventions. In addition, it was analyzed how this type of action can contribute to the continuation of this process since it ends up attracting and emerging a significant number of Non-Governmental Organizations to support the management of social assistance in Haiti. In order to reach the objective, specialized literature on natural disasters and vulnerability of the country in question was analyzed, in addition to documentary research carried out in newspapers, reports, reports and official data from the local government. Finally, it should be noted
\end{abstract}


that the State must prepare an infrastructure investment plan and make the population aware of leaving areas considered at risk, creating mechanisms so that they can be relocated to planned locations. Thus, the State will not be able to eliminate the risks associated with natural disasters but reduce losses in material goods and human lives.

Keywords: Natural Disasters; Vulnerability; International Agents; Territorial Sovereignty.

\section{INTRODUÇÃO}

Desastres naturais sempre ocorreram em diferentes partes do mundo, gerando impactos ambientais negativos em diversos aspectos e intensidades. Suas consequências são notadas em maior grau nas áreas onde as pessoas e seus bens estão frequentemente concentrados, corroborando para uma situação de vulnerabilidade (FERRETI, 2015). O conceito de vulnerabilidade pode ser definido como a suscetibilidade ou grau de incapacidade de lidar com efeitos adversos relativos às mudanças climáticas e/ou eventos extremos (IPCC, 2007), ou o grau de perda de um elemento ou conjunto de elementos em decorrência de efeito desastroso (UNDRO, 1979).

Após o terremoto de 2010, o Haiti se tornou um dos países mais afetados por eventos climáticos, sendo o que sofre maior número de desastres naturais do Caribe. O epicentro foi próximo a cidade de Léogâne, a $17 \mathrm{~km}$ ao sudoeste da capital Porto Príncipe, departamento de Oeste (BELLERIVE, 2010). Em 2008, tempestades tropicais e ocorrência de furacões na região resultaram em perdas estimadas em 15\% do PIB, seguido pelo terremoto de 12 de janeiro de 2010, que matou 220 mil pessoas, obrigou a locomoção de 1,5 milhões de cidadãos e causou prejuízo equivalente à 120\% do PIB (MEF, 2014), sendo as áreas mais urbanizadas as mais devastadas devido à expansão desordenada e sem infraestrutura adequada (COURBAGE et al., 2013).

Monteiro e Pinheiro (2012) enfatiza a compreensão de Maskrey (1993), ao apontar que o desastre natural é uma movimentação da natureza, ou seja, atribui-se a qualquer processo que a natureza adere como resultante da sua própria atividade interna capaz de gerar impactos na atividade humana ou não. Além disso, há fenômenos que podem ter certa regularidade, como também podem existir aqueles de aparição extraordinária e magnificente, os quais são imprevisíveis ou não. Nesse sentido, os eventos podem causar diversas reorganizações no tempo e no espaço entre sujeitos e objetos (SANTOS, 2004).

Em acordo com Ferreti (2015), destaca-se que quando um desastre natural ocorre, seu potencial de destruição é intensificado pela falta de estruturas urbanas e rurais adequadas, deixando a população ainda mais fragilizada. As evidências que corroboram com esta afirmação podem ser encontradas não só nas consequências dos desastres mais recentes, mas em toda a história do Haiti. Segundo relatório do Ministério da Economia e das Finanças - MEF, (2016), os efeitos adversos a 
estes eventos são muito graves no Haiti, provocando maior vulnerabilidade e fraqueza institucional no país.

Diante deste contexto, ajudas humanitárias emergenciais tem papel importante, entretanto, quando se torna estrutural, no sentido de substituir o papel do Estado em todas as esferas, o resultado é a relativa perda de poder e consequentemente da soberania nacional. No caso do Haiti, segundo Ricardo Seitenfus, em entrevista concedida ao jornal "Le temps" (ROBERT, 2010), levar ajuda humanitária com interesses para além da ajuda ao povo haitiano, pode ser considerado uma irresponsabilidade do poder coletivo envolvido, corroborando inclusive para o surgimento de epidemias, como a de cólera, por exemplo, que corroborou para prejudicar ainda mais o país.

Sendo assim, objetivo deste trabalho foi fazer uma análise sobre desastres naturais com enfoque no terremoto de 2010, utilizado como justificativa para a ampliação de agentes internacionais no território haitiano. Foi possível observar de que forma a debilidade das instituições estatais controlam grande parte da assistência social, partindo da discussão sobre a interferência dos países estrangeiros no território nacional na perspectiva de proteção de vidas e de prestar socorro à população em situação de risco no Haiti. Intervenções como estas podem dar suporte e corroborar para a continuação de políticas de dominação capitalista por meio de Organizações Não Governamentais (ONGs) e comunidades internacionais na gestão de assistenciais sociais no Haiti. Para se chegar ao objetivo, levantamento bibliográfico, documental e de campo foram utilizadas.

\section{DESASTRES NATURAIS: NOVO CENÁRIO PARA AMPLIAÇÃO DA VULNERABILIDADE NO HAITI}

Os desastres tendem a afetar os mais pobres, principalmente aqueles que se estabelecem em planícies inundáveis ou próximo ao litoral, especialmente no caso de tempestades tropicais, onde quase $50 \%$ dos danos e perdas nos setores produtivos se concentraram no setor agrícola (MEF, 2014). Este fato fez com que muitas Organizações não-governamentais (ONGs) se estabelecessem no território do Haiti para prestar serviço às pessoas, vítimas desses desastres que estavam em condições precárias após a tragédia de 12 de janeiro de 2010 por meio da ajuda humanitária (MEF, 2014).

As grandes potências econômicas intervêm nos países do terceiro-mundo para socorrer pessoas afetadas pelos eventos naturais como terremoto e furacões, e, com apoio de ONGs, atuam na distribuição da ajuda humanitária em áreas mais precárias. Os fenômenos naturais que afetaram o país, fazem com que o Haiti se torne objeto constante de intervenções internacionais.

Em relação da política de dominação dos países do centro de sistema capitalista, conforme Séguy (2014), o princípio das interferências das Organizações ou da Comunidade Internacional 
caminha no topo da soberania nacional da população haitiana, justificando que o papel da ONU não é, porém, uma função a trabalho do imperialismo, ou seja, defendendo os seus interesses. Logo, percebe-se que interesses facetados de ajuda humanitária não estão vinculados somente aos povos haitianos, mas também a interesses particulares de grandes potencias.

Santos (2008) considera o mundo como um conjunto de eventualidades, onde o evento pode ser o portador de uma ou mais oportunidades presentes na atualidade, podendo ser, inclusive, o vetor na formação social de uma região ou país. No entanto, o ponto de um evento determina a noção mais elementar da natureza ou do ambiente, levando em operação a realidade, em um determinado tempo e espaço geográfico.

\section{O TERREMOTO DE 2010 E SEUS IMPACTOS NO HAITI}

A população haitiana enfrentou o terremoto de 12 de janeiro de 2010 com a magnitude 7,3 na escala Richter, provocando uma série de desabrigados, feridos e mortos. Este foi o terremoto mais intenso no país em 200 anos, com tremores durante 35 segundos (MEF, 2014). Seus efeitos foram sentidos principalmente nos departamentos do Oeste, Sudeste e dos Nippes. A área metropolitana de Porto Príncipe foi a que sofreu danos mais significados (Figura 1).

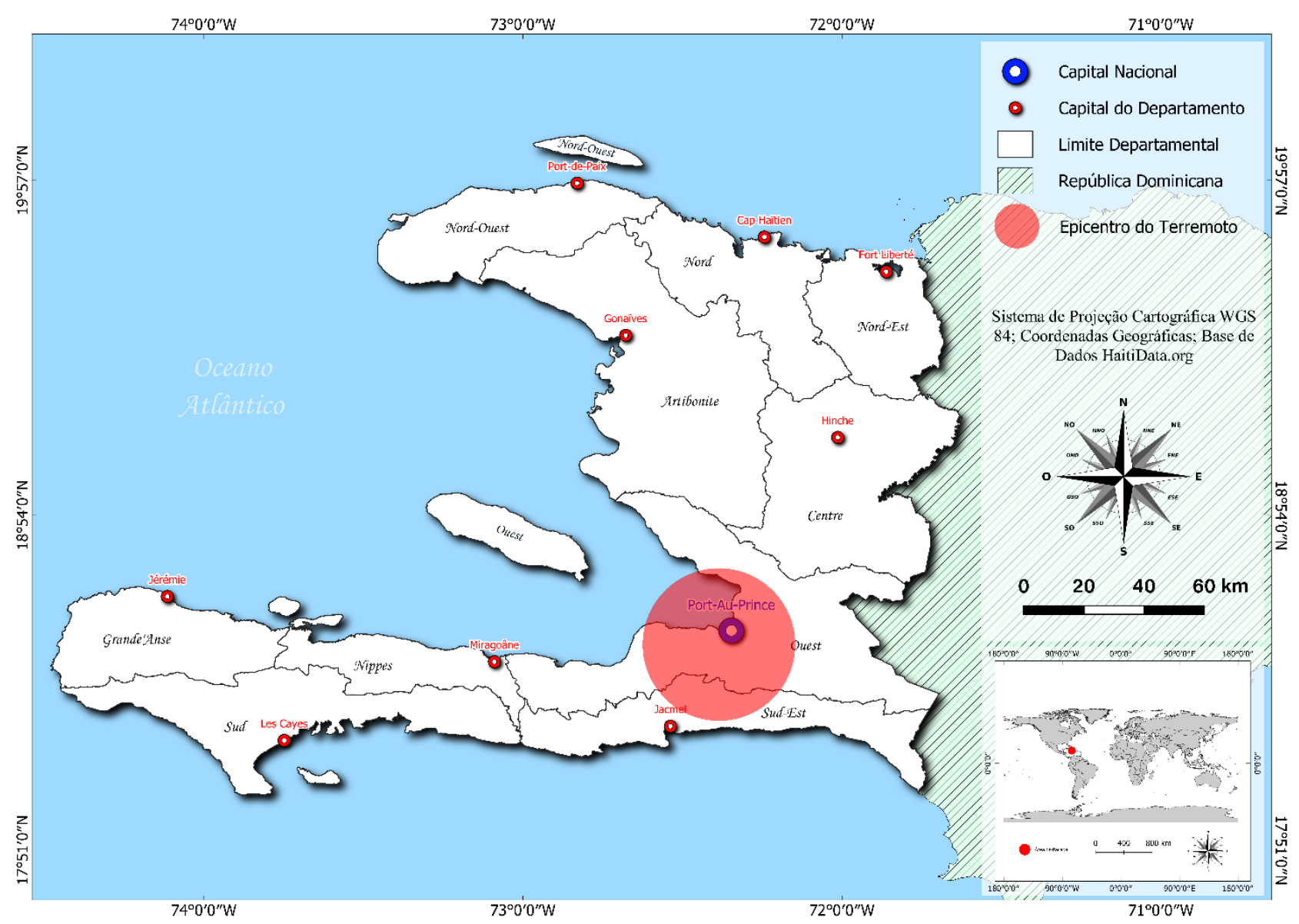

Figura 1 - Mapa de localização do Haiti com o epicentro do terremoto em destaque próximo a capital nacional. 
Fonte: Escritório das Nações Unidas para a Coordenação de Assuntos Humanitários, 2010. Elaboração: Autores (2020).

Neste contexto, o terremoto afetou a área mais povoada do país e principal centro econômico e administrativo. A situação é a mais trágica que o país conheceu após três anos de uma tendência à estabilização da situação sócio-política, de segurança, crescimento econômico e da melhoria das condições de vida da população. Nessa perspectiva, "os eventos quando acontecem dissolvem as coisas e também dissolvem as identidades, propondo-nos outras e mostrando que não são fixas" (SANTOS, 2008, p.146). Ade tragédia causou imenso impacto sobre uma população marcada pela pobreza (67\% delas viviam com menos de dois dólares diariamente, pouco antes do terremoto), com cerca de 1,5 milhões de pessoas (15\% da população nacional) foram diretamente afetadas e mais de 220.000 pessoas morreram, além 300.000 feridos (BELLERIVE, 2010).

Pelo fato de atingir o centro da economia e da administração do Haiti, afetaram-se drasticamente as capacidades da sobrevivência das vidas humanas, de instituições do setor público e privado, parceiros técnicos e financeiros internacionais e também algumas organizações não governamentais (ONGs) (BELLERIVE, 2010). Segundo Klein (2008), quando uma crise ou desastres naturais ocorrem, resultam em ideias que operam no território nacional. Se for observado no caso do Haiti, o Estado toma uma decisão racional para salvar a vida das pessoas que estão posicionadas na área de risco depois dos eventos naturais, desenvolvendo alternativas às políticas e as estratégias que estão presentes na realidade, conservando-a em realce, ainda que o politicamente inviável reconduza o politicamente irremissível.

Grande parte das pessoas que viviam no local do epicentro do terremoto, continuam no local após a situação desastrosa, com objetivo de tentar recuperar o que for possível diante do cenário de destruição, tentando reassegurar a relação e identidade com o lugar. Contudo, a maioria das pessoas deixaram a capital e região do epicentro para encontrar a família em outros departamentos do Haiti e causando um deslocamento massivo da população. De acordo com Coubarage (2013), após a ocorrência do terremoto, 1,3 milhões de pessoas passaram a viver em abrigos na região metropolitana de Porto Príncipe, capital do país e área mais afetada. Desta forma, os problemas sociais se intensificaram ainda mais na capital e região metropolitana.

\subsection{Consequências socioambientais e deslocamentos populacionais}

Segundo a USAID (Agência dos Estados Unidos para o Desenvolvimento Internacional) em 2010, ocorreram deslocamentos significativos de pessoas para diversas partes do país em busca de abrigos. Nesse sentido, 31.253 pessoas deslocaram-se para o Noroeste do país, 13.531 pessoas foram para norte, 7.740 pessoas se deslocaram para o Nordeste, e 90.000 de pessoas foram deslocadas para o Departamento do Centro (USAID, 2010). 
Destarte, 22.425 voltaram para o Sul, 30.000 pessoas para o Departamento do Nippe e 55.167 pessoas deslocaram-se para o Departamento de Grande-Anse. Já no departamento do Oeste, 704.776 pessoas foram para as cidades vizinhas e o número de pessoas que se mudaram para o Departamento de Artibonite foi de 160.000. As áreas consideradas mais afetadas registradas são: Léogane: 80 a 90\% foram destruídas; Petit-Goâve, 15 \%; Jacmel, 50 a 60\%; Carrefour, 40 a 50 \%; e Gressier, que teve de 40 a 50\% de área destruída.

No âmbito da infraestrutura, cerca de 105.000 casas foram totalmente destruídas e mais de 208.000 danificadas. Além disso, mais de 1.300 instituições de ensino, 50 hospitais e centros de saúde foram derrubados ou ficaram inutilizáveis. O porto principal do país ficou parcialmente inoperante, enquanto o Palácio Presidencial, Parlamento, Palácio de Justiça, os edifícios ministeriais e administração pública foram totalmente destruídos (BELLERIVE, 2010). O luxuoso Hotel Christophe, "base das operações civis da missão das Nações Unidas, também fora abaixo e parte do pessoal do alto escalão desta instituição estavam sob os escombros” (THOMAZ, 2010, p. 26).

Os danos e prejuízos causados pelo terremoto foram estimados em US\$ 7,8 bilhões, uma soma maior do que o PIB do Haiti em 2009. A maior parte ocorreu no setor privado, estimado em US\$ 5.722 bilhões, enquanto a participação do setor público totalizou US\$ 2.0814 bilhões. O valor dos ativos físicos destruídos, incluindo unidades habitacionais, escolas, hospitais, edifícios, estradas e pontes, portos e aeroportos - foi estimado em US\$ 4.302 milhões. A alteração dos fluxos econômicos (perdas de produção, redução do volume de negócios, perdas de emprego e aumento do salário nos custos de produção, dentre outros.) atingiu \$US 3.561 milhões (BELLERIVE, 2010).

O setor da habitação foi o mais afetado pelo terremoto, com os danos atingindo acerca de \$US 2,3 milhões. Isso representa cerca de $40 \%$ dos efeitos produzidos pelo desastre. Ao incluir o valor da destruição das unidades habitacionais, observa-se vários tipos e qualidades de imóveis parcialmente danificados, além de bens de consumo perdidos. Também deve-se notar que as perdas para a habitação são estimadas a US\$ 739 milhões e envolvem o custo de fornecer abrigo temporário, o custo da demolição e o valor das perdas de aluguel. Outros setores, em ordem decrescente de importância, no que diz respeito aos efeitos danosos são: o comércio (danos e perda de US\$ 639 milhões, ou 8\% do total), transportes e edifícios da administração pública (US\$ 595 milhões) e educação e saúde (com uma média de 6\% do total) (BELLERIVE, 2010). A tabela 1 apresenta os dados de cada setor referentes em consequência do terremoto. 
Tabela 1: Haiti - Avaliação de danos e perdas causada pelo terremoto de janeiro de 2010 (milhões de dólares).

\begin{tabular}{|c|c|c|c|c|c|c|}
\hline \multirow{2}{*}{ Temas/Subtemas } & \multicolumn{3}{|c|}{ Danos (em milhões de dólares US) } & \multicolumn{3}{|c|}{ Perdas (em milhões de dólares US) } \\
\hline & Público & Privado & Total & Pública & Privada & Total \\
\hline $\begin{array}{l}\text { Meio ambiente \& Gestão } \\
\text { dos riscos e desastres }\end{array}$ & 3,00 & 0,00 & 3,00 & 321,40 & 175,00 & 496,40 \\
\hline Setores Sociais & 153,8 & 805,40 & 959,9 & 197,8 & 355,00 & 553,30 \\
\hline Água e saneamento & 20,9 & 13,10 & 34,00 & 8,4 & 193,00 & 201,40 \\
\hline Saúde & 94,7 & 101,70 & 196,40 & 187,7 & 86,10 & 273,70 \\
\hline Educação & 38,2 & 395,60 & 434,00 & 1,7 & 41,50 & 43,20 \\
\hline $\begin{array}{c}\text { Segurança alimentar e } \\
\text { Nutrição }\end{array}$ & 0,00 & 295,00 & 295,00 & 0,00 & 35,00 & 35,00 \\
\hline Infraestruturas & 628,1 & 2538,60 & 3166,70 & 774,2 & 520,60 & 1294,8 \\
\hline Habitação & 0,00 & 2333,20 & 2333,2 & 459,4 & 279,3 & 738,7 \\
\hline Transporte & 188,50 & 118,6 & 307,1 & 91,6 & 197,50 & 289,1 \\
\hline Telecomunicações & 66,00 & 28,00 & 94,00 & 24,00 & 22,00 & 46,00 \\
\hline Energia & 20,8 & 0,00 & 20,8 & 37,3 & 0,00 & 37,3 \\
\hline $\begin{array}{c}\text { Infraestruturas urbanas e } \\
\text { Comunidades }\end{array}$ & 352,80 & 58,80 & 411,60 & 162,00 & 21,8 & 183,8 \\
\hline Setores Produtivos & 3,1 & 394,00 & 397,10 & 0,00 & 933,00 & 933,00 \\
\hline Agricultura & 3,1 & 49,9 & 53,00 & 0,00 & 96,0 & 96,0 \\
\hline Indústria & 0,00 & 74,6 & 74,6 & 0,00 & 267,7 & 267,7 \\
\hline Comércio & 0,00 & 148,7 & 148,7 & 0,00 & 490,6 & 490,6 \\
\hline Finanças e Banco & 0,00 & 98,2 & 98,2 & 0,00 & 0,00 & 0,00 \\
\hline Turismo & 0,00 & 22,6 & 22,6 & 0,00 & 79,0 & 79,0 \\
\hline Total & $1.572,1$ & $3.738,0$ & $4.526,2$ & $1.293,4$ & $1.984,50$ & $3.277,8$ \\
\hline
\end{tabular}

Fonte: Tabela criada pelo autor a partir dos dados adaptados pelo Plano de Ação para o Desenvolvimento do Haiti (DPNA), 2010.

De acordo com Thomaz (2010, p.26), que estava no Haiti no momento em que o terremoto aconteceu, "não se viam nem civis, tampouco militares das Nações Unidas, ambulâncias ou algum carro para recolher os corpos que se acumulavam pelas ruas”. Ainda segundo Thomaz (2010, p.26), “os haitianos pareciam saber que todo o efetivo militar da Missão das Nações Unidas para Estabilização do Haiti (MINUSTAH) se concentrava no trabalho de salvar os membros da ONU no Hotel Christophe com um efetivo acerca de 6 mil militares. Uma minoria estava trabalhando no Montana Hotel. Neste período, a ONU ajuda a ONU, os haitianos ajudam os haitianos, pois, os tremores continuavam" (ibidem, p.26). O autor analisa que após o terremoto, a maioria das pessoas iniciava o processo de preparação das tendas e, muitas vezes, sem participação de organizações internacionais, compartilharam comida e água. Segundo ele, o Champs-de-Mars foi transformado em campo de abrigo, modificado pela população que se improvisara e organizara barracas e tendas, com apoio de empresários haitianos.

Após o desastre de 12 de janeiro de 2010, a comunidade internacional desencadeou um dispositivo humanitário no território haitiano. Entre todos os atores a intervir, os americanos eram, sem dúvida, aqueles que oferecem a maioria dos recursos. O presidente estadunidense Barack Obama, declarou de fato que "este foi um dos maiores esforços de assistência na história recente 
dos EUA". Tais esforços foram confirmados por uma intervenção em 14 de janeiro sem pedido prévio ao presidente haitiano, René Préval, que tinha como papel central a reprodução de planos de ação desenvolvidos em contextos de guerra; em aquisição aeroportuária nacional; logística de ajuda humanitária, dentre outras.

Frisse (2010) ressaltou que no dia 17 de janeiro de 2010, ou seja, menos de uma semana após o terremoto, 5.800 militares norte-americanos da 22 $2^{\mathrm{a}}$ companhia da Marinha Expedicionária (2000) e 82 ${ }^{\mathrm{a}}$ Divisão Airborne foram estabelecidas no Haiti, apoiadas por aviões USS Carl Vinson Nuclear e seu grupo de batalha, além de navio-hospitalar. No entanto, no dia $1^{\circ}$ de fevereiro, as tropas dos EUA no Haiti aumentaram para cerca de 22.000 soldados, 15 navios e 58 aviões e helicópteros (FRISSE, 2010). Nessa perspectiva, a administração do Barack Obama justificou essa mobilização excepcional de recursos militares pelo ambiente operacional particularmente difícil. Os soldados norte-americanos foram utilizados, por um lado, para completar a polícia haitiana e a MINUSTAH, e por outro, para implementar uma cadeia de fornecimento robusta e implantar veículos de resgate pesados (FRISSE, 2010).

$\mathrm{Na}$ análise feita para Seitenfus (2002), o objetivo principal desse tipo de intervenção é restaurar o status quo, sem buscar uma vantagem visível para quem interfere na ação da ajuda do país, defendendo os interesses particulares de um agente ou de um grupo de atores. Nas palavras do autor, trata-se de exercício absoluto da potência mais forte e reproduz o estado de natureza hobbesiano no contexto internacional. Essa intervenção tem a ver com busca de ampliação das bases militares para proteger os interesses geopolíticos e geoestratégicos no Haiti.

Séguy (2014, p.91) baseia-se no pensamento de Manigat (2004, p. 246-7), ressaltando 5 razões causando a invasão das bases militares estrangeiras no Haiti: 1) sua posição geoestratégica ao canal de Panamá; 2) a necessidade de transformação econômica do Haiti e de cumprir seu papel na divisão internacional do trabalho; 3) o controle do seu comércio exterior; 4) sua dívida externa; 5) necessidade de comprovar que uma república negra é incapaz de se autogovernar.

Ainda antes da tragédia de 10 de janeiro de 2010, as tropas da MINUSTAH em comparação a intervenção dos soldados norte-americanos no Haiti eram muito menores. A força de paz composta de tropas internacionais, representando vários Estados, estavam presentes no território haitiano desde 2004, com 9 mil homens de suas tropas instaladas antes do desastre, enquanto após o terremoto o número chegou a 18 mil homens. Com o envio das tropas dos EUA, os números aumentaram mais que o total das tropas da ONU no Haiti, incluindo aqueles já presentes antes do terremoto sob a justificativa da ajuda humanitária.

Esse tipo intervenção nos remete ao pensamento do Seitenfus (2002, p.14), ao dizer que: “a invasão de um país pelo outro, ou qualquer dos muitos exemplos de ação militarizada, compõem estereótipos da intervenção, seja motivada ou não, seja aceitável ou não, é bem certo que existem 
formas não-militares e não solitárias de levar terceiros países a agirem de forma orientada por ditames exógenos. Portanto, essa ingerência representa hoje em dia um leque muito mais amplo do que esse fenômeno, unilateral e violento, que se poderia designar como intervenção armada".

Tippenhauer (2013) sublinha que a literatura deixa claro que a ajuda humanitária de emergência, quando inclui efetivos e operações militares, não pode se basear apenas sobre este aspecto. Portanto, as normas estabelecem que a força militar seja um auxílio, não o núcleo duro, devendo agir em cooperação, sem impor diretrizes ao poder local. Neste contexto, é importante perceber as marcas éticas e as motivações de ajudas humanitárias, seja preparada por um Estado ou oriundos de resistências políticas que empenham o domínio do poder (SILVA, 2015).

\section{AGENTES INTERNACIONAIS E AJUDA HUMANITÁRIA}

A ação de atores estatais, bem como o uso de tropas armadas, não é a regra no campo humanitário. Enquanto muitos conferem a própria utilidade e eficiência desses agentes, outros incorporam os chamados trabalhadores humanitários básicos e as ONGs (SEIXAS, 2008). Os Estados e exércitos estão cada vez mais implicados no sistema humanitário, assumindo progressivamente o seu lugar de fato. Diante disso, para tentar minimizar as possibilidades de recuperação, a comunidade humanitária tem cuidadosamente ordenado os termos de operações de Estado e especialmente militarizada, com o soldado constituindo o objetivo político por excelência (SILVA, 2015).

Neste contexto, o discurso que prevalece dos organismos internacionais é de que o desenvolvimento requer o crescimento econômico e o direito de exigir a democracia liberal, exigindo um contexto social pluralista e visivelmente não ideológico, no qual as ONGs e as diversas categorias da sociedade civil possam desempenhar um fundamento importante e decisivo quanto ao do governo. Esta intensificação dos direitos exige mecanismos semelhantes àquelas por meio do qual o mercado global é dirigido (DEAN; CIMADAMORE; SIQUEIRA, 2006). Sendo assim, o termo da responsabilidade de responder refere-se a noção da presença de um direito a instituída resposta frente a um delito da regra jurídica do Estado. Em suma, resta entender se o dever de defender, por meio do uso da força, pode evidenciar a legalidade e a legitimidade das interferências humanitárias (ARTIGA, 2012; RAMOS, 2004).

$\mathrm{Na}$ análise feita por Frisse (2010), o aumento da tendência no uso das forças armadas para lidar com civis em momentos de crises é significativo, citando exemplo da França, onde é relativamente comum militares serem requisitados para proteção contra intempéries, poluição ou mesmo epidemias. Desse modo, Seixas (2008) expressa que o humanitário é, desta maneira, um discurso político e moral, uma forma geopolítica que se manifesta sobre a vida humana e sua 
verificação, não à competência das pessoas e dos direitos particulares. Esta ideia remete-nos para a tese de Foucault (1976), de que a política moderna é estabelecida pelo surgimento da biopolítica, ou a incorporação da existência nas configurações de controle estatal.

A presença de ONGs aumentou de maneira significativa no território haitiano nas últimas décadas. Em 2012, o número de ONGs reconhecidas pelo Estado haitiano era de 595 enquanto antes do terremoto, havia 459 (PÉLISIER, 2013). Em função do campo de atuação, essas organizações são geralmente classificadas em quatro grupos: "humanitária", “desenvolvimentista", "ambientalistas" e "ativistas de direitos humanos". No primeiro caso, são utilizadas na ajuda de urgência em ocorrência de desastres naturais (inundações, terremotos, tsunamis) ou crise humanitária (guerra, conflito armado). Além dos Médicos sem Fronteiras (MSF), Médicos do Mundo (MDM) e Ação contra a Fome (ACF). Em segundo, as ONGs de desenvolvimento (“desenvolvimentistas") que atuam no domínio da luta contra a pobreza e procuram sensibilizar as pessoas em países ricos para os problemas de desigualdade. O Centro Canadense de Estudos e Cooperação Internacional (CECI) e da Cooperativa para American Relief Everywhere (CARE) fazem parte deste grupo de ONGs (ibidem, 2013).

Segundo Pélissier (2013) o terceiro grupo está relacionado às ONGs ambientais (ambientalistas) que atuam para a defesa e promoção do ambiente. Nas conferências intergovernamentais, representantes de ONGs ambientais interagem com os Estados, organizações internacionais e corporações transnacionais sobre questões ambientais como o aquecimento global, a biodiversidade, a energia nuclear e os organismos geneticamente modificados (OGM). Dentro deste grupo está Greenpeace, Fundo Mundial para a Natureza (WWF) e Friends of the Earth, dentre outras.

Finalmente, as ONGs de defesa dos direitos humanos, ativas na promoção e luta pelos direitos humanos. O seu alcance é muito amplo, fornecendo assistência jurídica a vítimas de conflitos armados e lutando pela abolição da pena de morte e pelas disposições discriminatórias existentes nas leis de alguns Estados democráticos. A Anistia Internacional (AI), a Federação Internacional para os Direitos Humanos (FIDH) e Human Rights Watch (HRW), dentre outras, são alguns exemplos. A Figura 3 apresenta a pluralidade das ONGs que atuam no território haitiano. 


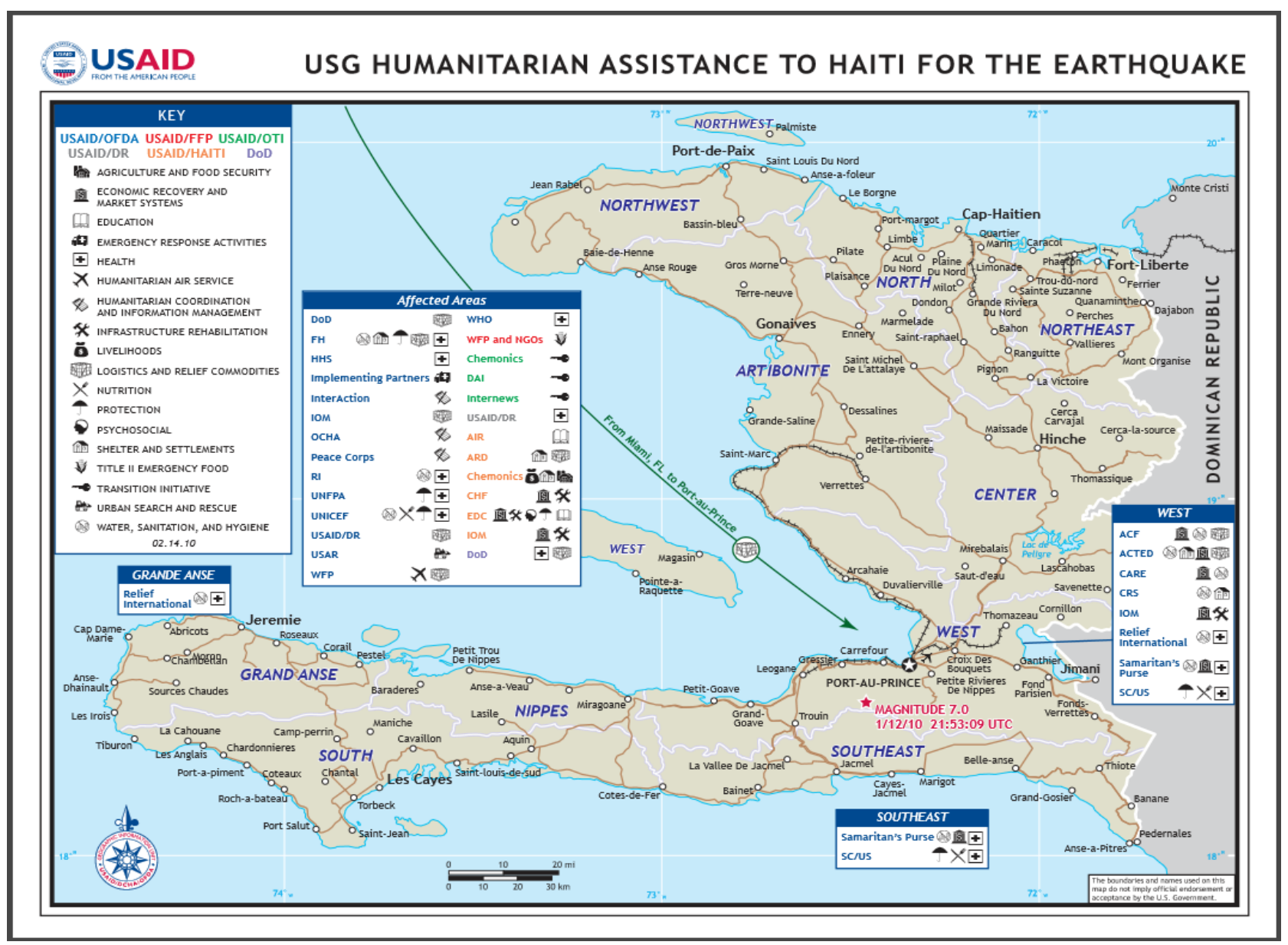

Figura 3 - ONGs internacionais participadas nas assistências humanitárias no Haiti. Fonte: USAID, 2010.

Para Carrière (2012), a participação de ONGs no Haiti não é meramente uma coincidência: muitos eventos e desastres (furacões, eventos políticos, terremoto) contribuíram para essa proliferação. Para controlar este fato, o Estado haitiano estabeleceu um quadro jurídico inicial e decreto que altera a lei que rege a elaboração e coordenação das ONGs, junto com o Ministério do Interior e Exterior. Existe uma relação desumana nas tomadas de decisão. De acordo com Seitenfus (2010), algumas ONGs só existem por causa da desgraça do Haiti e faz com que o país se torne mercadoria e laboratório para os envolvidos adquirirem experiência.

Nesse contexto, a ajuda humanitária obrigatoriamente é uma questão política, pois tem implicações sobre questões sociais, econômicas e culturais, atuando presencialmente em locais de conflito, com forças militares expostas aos interesses de atores políticos locais e externos, devendo saber lidar com os doadores e os meios de comunicação para melhor atingir seus objetivos. As atuações e êxitos dependem do nível de fraqueza dos estados onde estão atuando e atualmente enfrenta uma série de dilemas políticos e aceitação social em função de má conduta por parte de organizações que visam interesses particulares. 


\subsection{Agravação da situação socioeconômica no Haiti}

É sabido que os desastres naturais pesam fortemente sobre o desempenho econômico do Haiti e de qualquer país. Entre 1971 e 2013, a economia haitiana sofreu muitas instabilidades, cada uma com impacto negativo diferente. Estes variam de acordo com a natureza dos desastres: os efeitos das inundações, por exemplo, são geralmente limitados a algumas áreas e sentidas por menos pessoas do que furacões ou terremotos, que geralmente possuem consequências de maior alcance. Se considerar o ano de 2008, o país foi atingido por quatro furacões que causaram a queda na produção agrícola, enquanto em o terremoto de 2010 resultou em perdas humanas significativas e deslocamento em massa da população.

Em 2012, o país foi atingido por dois furacões (Isaac e Sandy) e uma seca, levando a um declínio de 1,3\% no setor agrícola. Já o ciclone Matthew devastou parte do país em 2016, atingindo principalmente o Sul e Sudeste (MEF, 2016). Desse modo, o Haiti vem enfrentando diversos eventos naturais com repercussão negativa. De acordo com os dados relatados pela Direção de Proteção Civil do Ministério do Interior (2016), 546 pessoas foram mortas, 128 pessoas desapareceram e 439 ficaram feridas, além de mais de 175.500 alocadas em 224 abrigos temporários. De modo geral, cerca de 2,1 milhões de pessoas foram afetadas pelo furacão de Matthew, dos quais 1,4 milhão estavam em situação de assistência social.

Esses eventos naturais causaram graves inundações, destruição de muitas infraestruturas urbanas, estradas, linhas de energia, residências privadas, edifícios públicos, hospitais, igrejas e escolas, que foram totalmente arrasadas e causaram impactos muito negativos significativos na agricultura e consequentemente no abastecimento da população. O furacão Matthew foi o último evento de grande magnitude a ocorrer no Haiti, e suas consequências, assim como de eventos passados, são sentidas até os dias atuais. Para melhor observar as perdas causadas pelo mesmo, a tabela 2 apresenta, em cada setor da economia do país, as em perdas e danos decorrentes do mesmo. Grande parte se deu nos setores sociais, como habitação, educação, setores produtivos, agricultura e comércio, infraestrutura, turismo e meio ambiente; respectivamente (MEF, 2016).

Tabela 2: Danos e perdas causados pelo furacão por setores da economia do Haiti.

\begin{tabular}{ccccc}
\hline Setores & $\begin{array}{c}\text { Danos em Milhões } \\
\text { de US\$ }\end{array}$ & $\begin{array}{c}\text { Perda em } \\
\text { milhões de US\$ }\end{array}$ & $\begin{array}{c}\text { Total de danos e perdas } \\
\text { em milhões de US\$ }\end{array}$ & $\begin{array}{c}\text { Total de danos e } \\
\text { perdas em \%o }\end{array}$ \\
\hline $\begin{array}{c}\text { Setores sociais } \\
\text { Alojamento e }\end{array}$ & $\mathbf{6 1 8 , 0}$ & $\mathbf{1 5 0 , 1}$ & $\mathbf{7 6 8 , 1}$ & $\mathbf{4 0 , 7}$ \\
urbanização & 536,8 & 59,6 & 596,4 & 31,6 \\
$\quad$ Saúde & 19,1 & 56,4 & 596,4 & 31,6 \\
Educação & 62,1 & 34,1 & 96,2 & 5,1 \\
Infraestrutura & $\mathbf{2 1 0 , 6}$ & $\mathbf{1 5 4 , 1}$ & $\mathbf{3 3 4 , 7}$ & $\mathbf{1 7 , 7}$ \\
Transporte e & 168,6 & 114,5 & 283,1 & 15 \\
telecomunicações & 20,6 & 5,2 & 25,8 & 1,4
\end{tabular}




\begin{tabular}{ccccc} 
Energia & 21,4 & 4,4 & 25,8 & 1,4 \\
& & & & $\mathbf{4 1}$ \\
Setores produtivos & $\mathbf{4 5 4 , 7}$ & $\mathbf{3 1 9 , 2}$ & $\mathbf{7 7 3 , 9}$ & 32 \\
Agricultura, pesca & 390,8 & 213 & 603,8 & 8,6 \\
Comércio e indústria & 59,7 & 102,4 & 162,1 & 0,4 \\
Turismo & 4,2 & 3,8 & 8,1 & $\mathbf{0 , 6}$ \\
Meio Ambiente & $\mathbf{1 1 , 2}$ & - & $\mathbf{1 1 , 2}$ & 0,6 \\
$\begin{array}{c}\text { Áreas protegidas e } \\
\text { parques nacionais }\end{array}$ & 11,2 & - & 11,2 & $\mathbf{1 0 0 , 0 0}$ \\
$\quad$ Total & $\mathbf{1 . 2 9 4 , 5}$ & $\mathbf{5 9 3 , 4}$ & $\mathbf{1 . 8 8 7 , 9}$ & \\
\hline
\end{tabular}

Fonte: Tabela elaborada pelos autores a partir dos dados adaptados pelo Ministério da Economia e Finanças do Haiti, 2016.

As principais catástrofes naturais e danos aos produtos aumentaram sem poupar virtualmente nenhuma região do mundo. Assim, o Haiti não escapa disso, é cada vez mais vulnerável a secas mais severas, choques sísmicos, precipitação mais violenta, inundações devastadoras ou furacões. Porém, essas consequências agravaram a situação socioeconômica do país, causando perdas e danos consideráveis na sociedade haitiana. De fato, uma das causas é a alta vulnerabilidade apresentada do Haiti aos riscos naturais.

As consequências da vulnerabilidade do Haiti frente a eventos naturais podem ser intensificadas devido à falta de coberturas vegetais, que representam atualmente um percentual inferior a $2 \%$. Outro fato que contribui é a urbanização desordenada das grandes cidades, em função da grande concentração de pessoas, o que contribui para que sejam áreas de maior vulnerabilidade durante a ocorrência de desastres naturais. Outros efeitos negativos estão associados à atenção e capacidade insuficiente para melhorar a qualidade de vida das pessoas, além de gerir os desafios associados à prevenção na ocorrência de eventos naturais de grande magnitude.

Nesse sentido, o Ministério da Economia e Finanças (2016) afirmou que as catástrofes naturais resultam um custo de orçamento significativo, sendo o custo fiscal anual médio estimado pelo governo em torno de $1 \%$ do PB. Este custo avalia danos causados pelos furacões tropicais no Haiti $(0,8 \%$ do $\mathrm{PB})$ e terremotos $(0.2 \%$ do $\mathrm{PB})$. Por falta de uma estratégia financeira para gerir esse risco e proporcionar uma margem orçamental, os desastres naturais requerem articulação adequada dos fundos públicos.

Observamos que durante as ocorrências de desastres naturais, várias organizações apoiaram o governo haitiano nas estruturas de sistema nacional em áreas de gestão de riscos e desastres, ao incluir a Cruz Vermelha haitiana, fundamental para pessoas em situações vulneráveis. Em suma, esses agentes internacionais sempre estão presentes no território haitiano, sob auspício da ajuda humanitária como facilitadora da assistência social a chegar em áreas mais vulneráveis. Diante disso, o evento natural muda o formato, mas as organizações não resolvem os problemas sociais (de habitação, infraestrutura, educação, dentre outros), fazendo com que a situação continue a se a agravar após a ocorrência do desastre. Com o passar do tempo, a situação de vulnerabilidade 
se sobrepõe após cada desastre, tornando o recomeço cada vez mais difícil para o Estado e a população haitiana.

\section{CONSIDERAÇÕES FINAIS}

O Haiti vem sendo ocupado por tropas internacionais e perdendo a sua soberania nacional há algum tempo. A recorrência de desastres naturais continua recorrentes em curto intervalo de tempo, fazendo com que o país sofra intervenções constantes advindas das grandes potências mundiais, que usam estes acontecimentos como justificativa para ampliação da ocupação e do controle do Estado haitiano. Nesse sentido, o objetivo do presente trabalho foi contemplado ao mostrar as consequências negativas na dinâmica socioespacial em um país que já possui problemas estruturais internos.

Cada desastre natural é responsável por um determinado impacto, seja diretamente na vida das pessoas, como a perda de habitação, ou indiretamente, como na produção agrícola e abastecimento interno por exemplo. Adicionalmente, o desmatamento e a ocorrência de epidemias contribuem para o êxodo rural, que acaba tendo consequência sobre a economia do Haiti e desenvolvimento dos centros urbanos. De fato, a economia do país desde a década passada está em colapso, suscitando de transformações para incorporar questões políticas que ocasionaram instabilidade e trazem consequências negativas ao investimento público e privado.

A ajuda humanitária trazida pela ONU no território de um Estado marginalizado não tem um planejamento de Estado nacional. Assim, como o Estado não tem clara aferição das consequências dos efeitos dos auxílios, é relevante refletir sobre os limites a serem impostos para evitar desperdícios na assistência recebida. Além disso, o envolvimento da ajuda dos países doadores leva o país recebedor a submeter-se a ordem da governança global para receber a assistência humanitária, que muitas vezes chega à população através de ONGs internacionais e não pelo governo. Nesse contexto, essa perturbação sociopolítica permitiu a atuação das tropas da MINUSTAH junto dos soldados norte-americanos no território do Haiti, além da ampliação da assistência internacional e benefício dos países doadores para proteger seus próprios interesses regionais e comerciais.

Percebe-se que os desastres naturais se tornaram elementos importantes para análise da vulnerabilidade de um grupo de populações específicas, que foi sempre negligenciado pelo Estado nacional. Nesse contexto, o Estado deve preparar um plano de investimento em infraestrutura e nos setores sociais (transporte e comunicação, saúde, educação, dentre outros) e conscientizar as pessoas a deixarem áreas consideradas de risco, criando mecanismos para que, ao longo do tempo, a população possa ser alocada para locais planejados e com segurança. Por fim, destaca-se que 
através deste eventual planejamento, o Estado não vai ser capaz de eliminar os riscos associados aos desastres naturais, mas vai conseguir reduzir as perdas em materiais e em vidas humanas.

\section{REFERÊNCIAS}

ARTIAGA, R. R. G. O Brasil e a intervenção humanitária no Haiti (2004-2011). 2012. 107 f. Dissertação (Mestrado em Economia Política Internacional) - Instituto de Economia, Universidade Federal do Rio de Janeiro, Rio de Janeiro, 2012.

BELLERIVE, J. M. Haïti: PDNA du tremblement de terre-evaluation des dommages, des pertes des besoins généraux et sectoriels. 2010. 120p.

CARRIÈRE, N.; CHOQUETTE, E. Collque Internacional sur le rôle des ONG em Haiti « Les ONG em Haiti: entre le bien et le mal». Observatoire canadien sur les crises et l' action humanitaire (OCCAH), 2012. Disponível em: < http://www.occah.org>. Acesso em: 12 fev. 2017.

COURBAGE, Y. Quelles solutions après le séisme en Haiti? Une enquête auprès des déplacés internes. ACP. 2012. 112p.

DEAN, H.; CIMADAMORE, A.; SIQUEIRA, J. A pobreza do Estado: Reconsiderando o papel do Estado na luta contra a pobreza global. 1. ed. Buenos Aires : Clacso Livro, 2006. 274p.

FERRETI, A. Les territoires face aux catastrofes naturelles: quels outils pour prévenir les risques? Paris: Conseil économiques, social environnemental, 2015.

FRISSE, N. La nouvelle vocation humanitaire des forces armées? Cairn Info, n. 79, p. 57-62, 2010.

KLEIN, N. A Doutrina do choque: a ascensão do capitalismo de desastre. Tradução Vania Cury. Rio de Janeiro: Nova Fronteira, 2008. 592p.

MEF - MINISTÈRE DE L'ECONOMIE ET DES FINANCES. Situation économique, financière, sociale en haïti en 2013 et perspectives à court terme, Haiti, 2014. Disponível em: http://www.mef.gouv.ht/upload/doc/DeeSituationEcFinSocHaitirev_20septembre2014.pdf. Acesso: 17 out. 2020.

MEF - MINISTÈRE DE L'ECONOMIE ET DES FINANCES. Evaluation rapide des dommages et des pertes occasionnés par l'ouragan Matthew et éléments de réflexion pour le relèvement et la reconstruction. $2016.113 \mathrm{p}$.

MINUSTAH - Missão de Paz das Nações Unidas - MINUSTAH. ONU/MINUSTAH. 2016. Disponível em: <http://www.minustah.org/>. Acesso em: 28 abr. 2017.

MONTEIRO, J. B.; PINHEIRO, D. R. C. O desastre natural como fenômeno induzido pela sociedade: abordagens teóricas e metodologias operacionais para identificação/mitigação de desastres naturais. Revista de Geografia, Juiz de Fora, v. 2, n. 1, p. 1-9, 2012.

OLIVEIRA, F. A. P. Participação Brasileira no Haiti como forma de incremento das relações sociais e econômicas entre o Brasil e o Haiti. Rio Janeiro, 2013. 
PÉLISSIER, P. E. Le rôle des ONG dans les pays en développement, le cas Haiti. 2013. 65 f. Monografia (Trabalho de Conslusão de Curso) - Faculté des Sciencies Sociales, Université d'Ottawa, Ottawa, 2013.

SANTOS, R. M. N. S. Intervenção e assistência humanitárias à luz do direito internacional. Revista Pensar, Fortaleza, v. 14, n.2, p. 348-365, 2008.

SEGUY, F. Para compreender a recolonização do Haiti. Revista Outubro, n. 22, p. 82-108, 2014.

SEITENFUS, R. Ingerência ou solidariedade? Dilemas da ordem internacional contemporânea. São Paulo em perspectiva, v. 16, n. 2, p. 12-26, 2002.

SEIXAS, E. C. C. Governação global e ajuda ao desenvolvimento: 'dilemas' das ONGIs nas periferias do sistema internacional. E-cadernos CES, n. 2, p. 1-20, 2008.

SILVA, R. L. O Kosovo, intervenção humanitária e a teoria da guerra justa: reações ao posicionamento de Jürgen Habermas. Juris Poiesis, v. 18, n. 18, p. 212-225, 2015.

THOMAZ, O. R. O terremoto no Haiti, o mundo dos brancos e o Lugawou. Novos Estudos, n. 86, p. 23-39, 2010.

TIPPENHAUER, J. G. Haïti x Intervention Humanitaire de la Puissance des Etats-Unis d'Amérique. Internacional: Jet d'encre, tribune independente pour une pensée plurielle, 2013. Disponível em <http://www.jetdencre.ch/haiti-jose-1709\#_ftn15>. Acesso em: 16 fev. 2013.

UNDRO - United Nations Disaster Relief Office. Natural Disasters and Vulnerability Analysis.

USAID - Terremoto de 12 de janeiro de 2010. Mapa de deslocamentos da população haitiana para suas cidades, Haiti, 2010. 